International Journal of Applied Linguistics \& English Literature

ISSN 2200-3592 (Print), ISSN 2200-3452 (Online)

Vol. 1 No. 1; May 2012

\title{
The Comparative Effect of Non-Task and Provide-A-Model Preparation Activities on EFL Learners' Vocabulary Retention
}

\author{
Mona Khabiri (Corresponding author) \\ English Department, Faculty of Foreign Languages \\ Islamic Azad University, Central Tehran Branch \\ Simayeh Iran Street, Shahrake Ghods, \\ Tehran 14676-86831, Iran
}

Tel: 0098-912-3395118 E-mail: monakhabir@ yahoo.com

Saeedeh Charmgar, M.A.

English Department, Faculty of Foreign Languages

Islamic Azad University, Central Tehran Branch, Iran

Tel: 00989123466933 E-mail: saeedeh_charmgar@yahoo.com

Received: 10-05- 2012

doi:10.7575/ijalel.v.1n.1p.113
Accepted: 28-05- 2012

Published: 31-05- 2012

\begin{abstract}
This study investigated the comparative effective of non-task preparation activities and providing a model as two types of pre-task activities on vocabulary retention of 60 EFL students from a language school in Karaj, Iran. The participants were sorted out of a larger population of 90 intermediate students based on their scores on a piloted Preliminary English Test (PET) and a vocabulary test. As a result of the two mentioned tests, first 65 participants were selected and then randomly divided into two experimental groups: non-task preparation activities group and providing a model group. However, the results of five participants who did not attend the classes regularly during the treatment were finally discarded. The two experimental groups received different treatments. In one class, vocabularies were taught through doing some non-task preparation pre-task activities by the learners and in the other, the teacher provided the model of doing the activity. At the end of the treatment period, the researchers administered a vocabulary retention posttest. Analyzing the collected data through an independent samples $t$-test revealed that non-task preparation pre-task activities had a significantly higher impact on the vocabulary retention of the participants. The significant difference between the two pre-task activities is interpreted to be the possible outcome of the difference in the type of schemata each activates and the type of load each reduces.

Key words: non-task preparation activities, providing a model, vocabulary retention, TBLT, pre-task phase 1. Introduction

The issue of selecting the teaching method, approach, and strategy that serves each context best has always been a major challenge in EFL/ESL history. Richards and Rodgers (2001) state that considering different methods throughout history, foreign language learning and teaching has been the center of discussions and an important practical concern. Schmitt (2000, p. 15) states that "language teaching methodology has swung like a pendulum between language instruction as language analysis and language use. Likewise, vocabulary has had differing fortunes in the previous approaches". One major reason for the 'swing of the vocabulary pendulum' might have been its importance in language learning and teaching. According to Nunan (2001) vocabularies are the "fundamentally important aspect of language development" (p. 103) and Brown (2001) regards vocabularies as "basic building blocks of language ... and [vocabularies] are among the first priorities" (p. 377). Likewise, Harely (as cited in Wang, 2009) recognizes vocabulary as the unique way of improvement in language acquisition.

Vocabulary teaching, as a result, has been treated differently during the past years from presenting vocabularies as a long list of words to presenting them in a context or through various tasks. It is believed that the way vocabulary is presented affects its acquisition. For example, Tajeddin and Chiniforoushan (2011) cite various authors (i.e., Coady, 1997; Nation \& Newton, 1997; Paribakht \& Wesche, 1997; Zimmerman, 1997) who believe that "different Page | 113
\end{abstract}




\section{파망 \\ International Journal of Applied Linguistics \& English Literature \\ ISSN 2200-3592 (Print), ISSN 2200-3452 (Online)}

Vol. 1 No. 1; May 2012

modes, affected by different models of the nature of vocabulary and vocabulary acquisition and use, are favored" (p. 114). This might be the direct consequence of what Richards and Rodgers (2001) highlight as the recognitions that have caused the change in teaching methods in general: recognition of changes in the kind of proficiency learners need and changes in language and language learning theories.

Perhaps one of the most important of such recognition has been the acknowledgment of learners' need for communicative competence which manifested itself as the weak and strong versions of Communicative Language Teaching (Ellis, 2003) with the latter version leaving a great and durable impact on EFL/ESL contexts and is known as 'Task-Based Language Teaching' (TBLT).

1.1 Tasks and the Stages of Implementing Tasks in TBLT

Undoubtedly, tasks are the center of TBLT. Skehan (2003) mentions that the term 'task' replaced 'communicative activity' which used to be the core element in communicative approaches and thus was used during the 1970s and 1980s. Ellis (2006) believes that TBLT proposes task to be the most important element in the language classroom providing contexts for triggering learner acquisition processes and further learning.

There are diverse definitions for task in the literature, each pointing to or highlighting one or some aspects of a task. For example, Bygate, Skehan, and Swain (as cited in Chen \& Chen, 2008) believe that task prompts learners to use the language in order to achieve an objective while focusing on meaning. The prominence of 'objective' and 'focus on meaning' is also evident in how Ellis (2003) defines a task as "a work plan that requires learners to process language pragmatically in order to achieve an outcome" (p. 16). Some also believe that tasks are subsets of techniques and thus, to implement tasks, one in fact may need to apply some techniques (Nunan, 2004). Prabhu (1987), however seems to base his definition on a more psychological basis, though still maintaining 'objective' as the core component of task, by asserting that "an activity which required learners to arrive at an outcome from given information through some process of thought, and which allowed teachers to control and regulate that process, was regarded as a task" (p. 24). However, Willis and Willis (2007) believe that tasks are any activity done in the classroom and state that the teacher-led introduction is a task in itself because "It involves a genuine exchange of meaning, in which learners are required to process language for meaning and it also serves a priming function" (p. 21).

Other definitions of task have focused more on delineating the difference between tasks and exercises or other language or communicative activities. Crooks and Chaudron (1991) consider activities as a general term and tasks as a means for practicing language to engage students to work with each other to obtain an outcome. Ellis (2003) distinguishes between tasks, where the primary focus is on meaning, and exercises, where the primary focus is on form. Using the criteria, he reviews a number of activities commonly used in classroom teaching to determine to what extent they can be said to be tasks or exercises. His examples show that it is not always possible to clearly distinguish between the two as they "manifest features of both" (p. 16).

Regarding their types, tasks can be real world tasks or pedagogical tasks with the latter being the focus in this research, that is, those tasks that "occur in the classroom" (Nunan, 2004, p. 1), and "form the nucleus of the classroom activity" (Brown, 2001, p. 242). Nevertheless, note has to be taken that tasks can also be used for measurement purposes in research (e.g., studies cited in Zheng, 2009, for measuring vocabulary familiarity by prompting them through tasks). According to Nunan (2001), classroom tasks can lead to the ability to communicate in real world whether such tasks are real tasks or pedagogical ones. By considering the previous research studies, Garret and Shartall (as cited in Rivers, 2008) and Lam (as cited in Rivers, 2008) believe in the effectiveness of pedagogical tasks for being learner-centered. Moreover, Brown (2001) asserts that the goal of pedagogical tasks is to make the students ready for doing real world tasks.

For effective implementation of pedagogical tasks inside the classroom, often one issue is how to approach a task, or as Ellis (2003) maintains, "How a task can be fitted into a cycle of teaching" (p. 33). For this purpose usually different stages are considered in performing a task, which reflect what Ellis defines as "the chronology of a task-based lesson" (p. 243). As an illustration, Willis (1996) sets down a task cycle consisting of three phases of pre-task, task, and language focus and maintains that attention to form can be evident in all three stages. Others like Ellis consider the same three stages but more generally name them as pre-task, during-task (or while-task), and post-task phases or activities. In the pre-task stage, the focus is usually on getting prepared for the main while-task activities "in ways that will promote acquisition" (Ellis, 2003, p. 244). Skehan (1996) considers pre-task as a kind of pre-teaching and setting up the relevant language for a task and provides two alternatives for this phase with the emphasis being put either on the cognitive demands of the task or on the linguistic factors. Skehan, however, concludes that "engaging in activities which reduce cognitive load will release attentional capacity for the learner to concentrate more on linguistic factors" (p. 25). 


\section{파망 \\ International Journal of Applied Linguistics \& English Literature \\ ISSN 2200-3592 (Print), ISSN 2200-3452 (Online)}

Vol. 1 No. 1; May 2012

The importance of the pre-task stage is often highlighted in the literature on TBLT. Prabhu (1987, p. 29), for instance, believes that a half or two-third of the time of the class can be allocated to the pre-task phase doing "teacher directed, whole-class activity while the rest was used by the learners for working on their own". Although majority attribute the importance of pre-task stage to its function in giving instruction and preparing the students for the main task (e.g, Beglar \& Hunt, 2002; Boston, 2008; Lee, 2000; Richards, 1999), many also emphasize its role in motivating the students (e.g., Dörnyei, 2001; Willis, 2006; Verhelst, 2002). Yet others assert that the pre-task stage, just like the during-task stage, can provide the opportunity for focusing on and learning language forms (e.g., Beglar \& Hunt, 2002; Richards, 1999; Willis, 1996, Willis \& Willis, 2007) such as new vocabularies or the general language the learners need for doing the task. Furthermore, the pre-task stage can also make learners familiar with the communicative goal and context of the task (Boston, 2008). Finally, Ellis (2006) states that "the teacher, as an expert, uses the pre-task to scaffold learners' performance of the task with the expectancy that this 'other regulation' facilitates the 'self-regulation' learners will need to perform the main task on their own" (p. 3). Ellis (2003) recognizes four ways to handle pre-task phase; providing a model, non-task preparation activities, performing a similar task, and strategic planning. Preparing the learners and making them cognitively and linguistically ready for performing a task can be done by providing them with a model of the task. Ellis $(2006$, p. 3) describes this type of pre-task activity as "asking the students to observe a model of how the task can be performed without requiring them to undertake a trial performance of the task". Ellis (2003, p. 246) pinpoints that, "Minimally this involves presenting them with a text (oral or written) to demonstrate an 'ideal' performance of the task".

Alternatively Willis (1996) suggests asking two students to perform the task so that others can watch them or the teacher playing the audio or video recordings of fluent speakers performing the task. Willis (1990) believes that the teacher can help the students to have a better production by 'modeling' them the language. By providing a model, learners can observe a model to see how to perform a task and it has some positive effects on reducing the cognitive load by activating learners' content schemata (Ellis, 2006; Willis, 1996).

Non-task preparation activities, on the other hand, revolve around triggering the background knowledge of the learners and clarifying the topic area. As Ellis (2003) maintains varieties of activities are suggested under this category with the unified focus of minimizing the "cognitive and linguistic demands" (p. 246) of the task. According to Ellis (2003) in order to clarify the theme and topic of a task, one can activate the learners' schemata or give them some information related to the topic as background knowledge (p. 246).

This type of pre-task activity is, thus, based on schema theory which according to Nunan (2001) "is based on the notion that past experiences lead to the creation of mental frameworks that help us make sense of new experiences" (p. 201). Moreover, connecting new information with previous knowledge results in better retention of newly learned language (Hulstijn \& Laufer, 2001). Ellis (2006) believes that to clarify the theme or topic of a task, the learners' background knowledge or schemata can be activated. To obtain this aim, Willis (1996) proposes a series of activities such as classifying words and phrases, brainstorming, and mind-maps. However, Ellis (2003) maintains that the suggestions in the literature for minimizing the linguistic demands of the task through this type of pre-task activities seldom focus on grammar and more highlight vocabulary as it is believed that vocabulary is more central to task performance.

In this regard, Ellis (2003) refers to the three ways Newton proposes for teachers to focus on vocabulary during the non-task preparation activities as predicting (i.e., asking learners brainstorm as many related words to the topic as possible), cooperative dictionary search (i.e., assigning certain words to the learners to look up in the dictionary), and words and definitions (i.e., matching words to their definitions in a list).

\subsection{Vocabulary Retention}

As discussed earlier, vocabulary teaching and learning has been approached differently during the history of language teaching and learning. There has been an obvious movement from asking the learners to memorize a list of words and rote learning to teaching the words in meaningful context. In this line, Nunan (2004) indicates that it is generally accepted that language is more than a set of grammatical rules, with attendant sets of vocabulary, to be memorized. It is a dynamic resource for creating meaning. Learning is no longer seen simply as a process of habit formation (pp. 6-7).

There is abundant evidence that memorization of word lists does not comprise an effective vocabulary learning and retention strategy. Such evidence dates back to 1950s; for example, Miller (1956) maintained that Short Term Memory had a limited capacity of around 7 'chunks' of information and that such a limitation would, under some conditions, impede learning. It seems that the more learners are actively involved in the process of learning the language by observing and using it actively in the context, the more deeply they process it. Craik and Lockhart (1972) and Craik and Tulving (1975) maintained that a stimulus' mental processing depth is determined by five

Page $\mid 115$ 
International Journal of Applied Linguistics \& English Literature

ISSN 2200-3592 (Print), ISSN 2200-3452 (Online)

Vol. 1 No. 1; May 2012

factors: connections with pre-existing memory, time spent processing the stimulus, cognitive effort, self-reference effect, and sensory input mode. On equal grounds, Nemati (2010) believes that processing the language deeply is something that should be taught to the learners as it leads them to long term retention.

Vocabulary retention appears to be no exception as Hulstjin and Laufer (2001) assert that, "Cognitive psychologists agree that processing new lexical information more elaborately will lead to a better retention than if it had been processed less elaborately" (p. 451). They further maintain that processing the meaning of a word happens at a deep level, but its phonological form at a shallow level. Likewise, Schmitt (2000) believes that mere exposure to language does not guarantee that learners can acquire enough vocabulary, but to be engaged with words meaningfully can be a good way to practice language. The basic contention of the Involvement Load Hypothesis according to Hulstijn and Laufer (2001) is that retention of unfamiliar words is, generally, conditional upon the degree of involvement in processing these words; 'The greater the involvement load, the better the retention' (p. 245). And it is important to note that successful retention along with correct use will ultimately result in productive vocabulary (Vasiljevic, 2009).

One plausible alternative to activities that result in shallow processing of vocabulary seems to be the use of language tasks and incorporating vocabulary into different stages of task performance. The reason is that there is a consensus on the issue that performing a task requires several cognitive processes and the controversy, according to Ellis (2003), is only over the nature of such processes (e.g., Richards, Platt, \& Weber, as cited in Ellis, 2003; Nunan, as cited in Ellis, 2003; Prabhu, 1987). As Ellis (2003) asserts, one rationale for task-based syllabus is 'learner engagement' and maintains that 'tasks, as long as they provide a 'reasonable challenge', will be cognitively involving and motivating" (p. 209). Conclusively, practicing vocabulary as part of task performance may bring about the motivation and engagement required for deeper processing and hopefully more effective retention.

One concern, however, may be at which stage of task performance to focus on vocabulary. Skehan (1996) believes that vocabulary can be the focus during the pre-emptive, in-task, and post-task stages. However, he highlights pre-teaching vocabulary for its advantage in creating the opportunity for the learners to face necessary vocabularies they need before performing the task, and consequently, reducing the 'processing load' which is considered by Nunan (2004) to be an important issue: "Learners and the cognitive processes they engage in as they learn are seen as fundamentally important to the learning process" (p. 7). Likewise, Willis and Willis (2007, p. 72) suggest that 'through priming the processing load will be lightened'.

1.3 Purpose of the Study

In the milieu of the presented theoretical background, on one hand approaching vocabulary through tasks in a TBLT context was argued to be effective and promising and on the other hand, focusing on vocabulary during the pre-task phase was alleged to minimize the cognitive and linguistic load during the while-task phase and thus resulting in better task performance and more effective learning. Therefore, this study intended to compare the effect of two of the four suggested pre-task activities by Ellis (2003) on vocabulary retention. More specifically, the purpose of the study was to investigate whether non-task preparation and providing a model as two pre-task activities had different impacts on intermediate EFL learners' vocabulary retention. Therefore, the following research question was posed:

Q: Is there any significant difference between the effect of providing a model and non-task preparation pre-task activities on EFL learners' vocabulary retention?

To answer the research question the following null hypothesis was stated:

$\mathrm{H}_{0}$ : There is no significant difference between the effect of providing a model and non-task preparation pre-task activities on EFL learners' vocabulary retention.

\section{Method}

\subsection{Participants}

The participants of this study were 65 female students sorted out of a larger population of 90 intermediate students studying English as a foreign language at a language school in Karaj (a city close to the capital city of Tehran). The participants' age ranged from 15 to 35 and they had minimum two years of English learning experience. The selection procedure took place at two stages. At the first stage, the homogeneity of the aforementioned participants was confirmed based on their scores on a Preliminary English Test (PET) which was piloted in advance. That is, 67 participants were selected as those who obtained a score falling one standard deviation above and below the sample mean.

During the second stage, the 67 selected participants sat for a piloted 88-item vocabulary test to ensure their homogeneity in terms of vocabulary knowledge and to indentify the vocabularies that were unknown by all participants. Two participants who knew $10 \%$ of the vocabularies were omitted and the result was selection of 65

Page | 116 


\section{파망 \\ International Journal of Applied Linguistics \& English Literature \\ ISSN 2200-3592 (Print), ISSN 2200-3452 (Online)}

Vol. 1 No. 1; May 2012

participants. These participants were then randomly assigned to two experimental groups: 32 participants comprised the non-task preparation activities group and 33 participants formed the providing a model group. The two experimental groups received two different treatments for learning vocabularies. However, the results of two participants in the non-task preparation group and three in the providing a model group were omitted from the final analysis as these students were spotted as those who did not attend the classes regularly and thus were not representative of their group.

\subsection{Instruments}

The instruments used in this study included three tests, the course book, and the tasks and activities utilized for each group.

2.2.1 Proficiency Test

A sample PET was administered to the participants for the purpose of ensuring their homogeneity vis-á-vis their language proficiency as the first step in the study. PET had two papers: Reading and Writing and Listening. The reading and writing paper consisted of 35 reading questions in the form of multiple-choice, matching, and true-false items and the seven writing tasks in the form of sentence transformation questions and essays. One hour and thirty minutes were allocated to this paper. The listening paper, however, consisted of 25 multiple-choice, gap-filling, and yes/no questions with a thirty-minute time allocation. Note has to be taken that since the purpose of the study was investigating the impact of the two modes of pre-task activities on the vocabulary retention of the students, the speaking section of PET was not administered. Finally, PET's 'General Mark Scheme' was utilized for rating the two essays of the writing section.

\subsubsection{Vocabulary Pre- and Post-Test}

A vocabulary test was designed based on the content of the five reading passages of the book 'Intermediate Select Reading' which was practiced during the treatment. The test comprised a list of 96 vocabularies which were supposed to be unknown to the intermediate students according to one of the researcher's experience in teaching that level for years. The participants were asked to write either the Persian meaning or the English equivalent for each of the vocabularies on the list.

In the pilot phase eight vocabularies which were known by $60 \%$ of the participants were omitted from the list leaving the final list with 88 vocabularies to be administered for the pre-test. However, as a result of the main administration of the vocabulary list for homogenizing the participants during the pre-test, three of the vocabularies which were answered by five percent of the participants were also omitted from the list. So, there remained 85 vocabularies to be taught during the treatment, which were all unknown to the participants of the study. In order to come up with the vocabulary list for the post-test, the researchers randomly selected 40 vocabularies from the final 85 vocabularies which were taught during the treatment sessions. The participants were asked to write either the Persian meaning or the English equivalent for each word on the list.

2.2.3 Instructional Material

The book 'Select Readings' (Intermediate) by Lee and Gundersen (2001) was used as the course book. Moreover, activities for pre-tasks were selected from 'Doing Task-based Teaching' by Willis and Willis (2007) which will be fully described in the procedure section.

\subsection{Procedure}

At first, a piloted PET was administered to 90 intermediate students and those whose scores fell within one standard deviation above and below the mean $(\mathrm{M}=43.57, \mathrm{SD}=11.58)$ were selected. The application of Cronbach's alpha demonstrated that the reliability of the closed-ended items of PET was .83. Moreover, the inter-rater consistency for rating the essays in the writing section as measured by Pearson correlation turned out to be .91 .

As the second step, the piloted 88-item vocabulary pre-test (as explained before) was given to the participants and two students who knew $10 \%$ of the vocabularies were also omitted from the final sample. The remaining 65 participants were then randomly assigned to two experimental groups with an assurance that the two groups bore no significant difference in terms of their overall language proficiency as well as vocabulary knowledge.

The whole research project took place in 12 instructional sessions each lasting for 45 to 60 minutes. During these sessions, 85 vocabularies were taught through five reading texts selected from 'Select Reading' book to both groups with approximately seven vocabularies covered in each session. Each passage was split into two or three sections based on its length and each section was covered in one session in a way that each session around seven vocabularies would be introduced. The same teacher (one of the researchers) taught the two experimental groups and the two groups received same hours of instruction, reading passages, vocabularies, and the while-task and post-task activities. The only difference between the two groups was the type of pre-task activities through which the vocabularies were presented.

Page $\mid 117$ 


\section{파망 \\ International Journal of Applied Linguistics \& English Literature \\ ISSN 2200-3592 (Print), ISSN 2200-3452 (Online)}

Vol. 1 No. 1; May 2012

For both groups, the teacher conducted a warm-up using a picture and the title of the text. Then, the pre-task phase would start and continue for around thirty minutes for each group but through two different types of activities. For the non-task preparation activities group, the teacher would conduct brainstorming and asking participants to mention as many related words to the topic as possible. This was followed by several activities with a shared focus of gradually introducing the vocabularies and helping the participants guess their meaning before the main task. One of the activities was 'sequencing' in which some sentences were presented to the students which they were encouraged to re-order through recognizing the main and supporting ideas and the sequence of events. Some parts of these sentences were underlined which were the definition or synonym of the new vocabularies in the main text. Thus, the students would do the task through scanning the text, finding the vocabularies presented in the main text that matched the underlined definitions or synonyms in the sentences, and finally re-ordered the sentences.

Other tasks for the non-task preparation activities group were matching vocabularies with the definitions, matching the vocabularies with the meanings (synonyms) through finding lexical relations (parts of speech), and filling in the blanks through finding the meaning of the required vocabularies in the text. The basis for all these pre-task activities was scanning and skimming the text and guessing the meaning of the vocabularies.

In the providing a model group, all the activities that were done by the participants during the pre-task phase in the non-task preparation activities group (explained above) were carried out as a model by the teacher. In fact, the teacher provided the group with a model of the task performance. Through thinking aloud, the teacher demonstrated all the steps of each activity; for example how she scanned the text for the intended vocabulary, skimmed the paragraph or part of it, and used the text and the context to reach the best and most appropriate meaning for each of the above activities. The participants followed her to be able to guess the meaning of the vocabularies and were thus cognitively active during the whole process and the last and most important step for them was finding out the suitable meaning. Therefore, although the students finally performed the activities themselves, they first received a model on how to conduct them.

As mentioned before, the while- and post-task phases were exactly the same for both groups. The while-task phase was reading the text silently during which the teacher would guide the students in case they faced any problem. For the post-task phase, the participants in both groups were encouraged to take part in activities in which they would practice the same vocabularies such as: fill in the gaps, true/false, multiple choice comprehension questions, paraphrasing, and finally communal memory task for which the participants were encouraged to write a summary of the text using as many new vocabularies as they remembered. During all these three phases, the participants received feedback from the teacher since as Liu (2011) maintains feedback has a great role in ensuring the students of the correctness of their contextual guesses.

Note has to be taken that the students were not told that they were supposed to take part in a subsequent test to measure their vocabulary retention. Since the focus was on the retention of vocabularies, the vocabulary post-test was administered after a two-week interval and the results of the two groups were compared to determine the efficacy of the pre-task activities.

\subsection{Data Analysis}

Based on the nature and the purpose of the research, the design was experimental comparison-group as participants were randomly selected and assigned into two experimental groups. The major variables which the researchers manipulated in this study (independent variables) were non-task preparation activities and providing a model as two types of pre-task activities. Vocabulary retention was the dependent variable and language proficiency level of the participants, vocabulary knowledge, and gender were the control variables.

\section{Results}

The results of administering the piloted PET among 90 intermediate students were used for homogenizing the participants. For this purpose the descriptive statistics of the results were obtained and the reliability of different sections (reported in the instruments section) were estimated. Table 1 demonstrates the descriptive statistics of PET.

\begin{tabular}{lccc}
\multicolumn{4}{l}{ TABLE 1: Total Scores on PET } \\
& $\mathrm{N}$ & Mean & Std. Deviation \\
\hline PET Scores & 90 & 43.57 & 11.58
\end{tabular}

Following the selection of the participants based on the PET results, the 67 students sat for the vocabulary pre-tests and two students who knew $10 \%$ of the vocabularies were omitted from the target sample, thus the 
International Journal of Applied Linguistics \& English Literature

ISSN 2200-3592 (Print), ISSN 2200-3452 (Online)

Vol. 1 No. 1; May 2012

remaining 65 participants did not have knowledge of the target words and their scores on the 88-item vocabulary pre-test ranged between 0-3.

Subsequently, the participants were randomly assigned to the two experimental groups and at the end of the treatment they took the vocabulary post-test. As mentioned before, on the whole the results of five participants from the two groups were discarded for the final analysis as they did not attend their classes regularly, leaving the number of participants 30 in each group. The purpose of the vocabulary post-test was to investigate which group had a significantly higher vocabulary retention. Since the two groups bore no difference in terms of their general proficiency as well as knowledge of the target vocabularies prior to the treatment, any significant difference on the post-test between the two groups could be attributed to the differential impact of the pre-task activities which comprised the only difference in the procedure followed in the two groups. Therefore, first the descriptive statistics of the post-test were obtained for the target analysis. Table 2 demonstrates the results.

TABLE 2: Descriptive Statistics for the Vocabulary Post-Test

\begin{tabular}{|c|c|c|c|c|c|c|c|}
\hline \multirow[t]{2}{*}{ Group } & \multirow[t]{2}{*}{$\mathrm{N}$} & \multicolumn{2}{|c|}{ Mean } & \multirow{2}{*}{$\begin{array}{c}\text { Std. } \\
\text { Deviation }\end{array}$} & \multicolumn{3}{|c|}{ Skewness } \\
\hline & & Statistic & Std. Error & & Statistic & Std. Error & Ratio \\
\hline $\begin{array}{l}\text { Non-task } \\
\text { preparation }\end{array}$ & 30 & 24.17 & 1.135 & 6.215 & 0.028 & 0.427 & 0.065 \\
\hline $\begin{array}{l}\text { Providing a } \\
\text { Model }\end{array}$ & 30 & 20.80 & 1.197 & 6.557 & 0.076 & 0.427 & 0.177 \\
\hline
\end{tabular}

As shown in Table 2, non-task preparation group obtained a higher mean than the providing a model group on the vocabulary post-test. However, to test the null hypothesis of the study, group means had to be statistically compared through an independent samples $t$-test. Therefore, the noramality of both distributions of scores as the assumption for running $t$-test was checked first. As demonstrated in Table 2, the skewness ratios for both groups (.065 and .177) fell within the acceptable range of \pm 1.96 meaning that both sets of scores were normally distributed and running a $t$-test was legitimate. Table 3 demonstrates the results of the $t$-test.

TABLE 3: The Result of Independent Samples $t$-test for Comparing the Vocabulary Retention Post-test Mean Scores of the Two Experimental Groups

\begin{tabular}{|c|c|c|c|c|c|c|c|}
\hline & $\begin{array}{r}\text { Lever } \\
\text { Equality }\end{array}$ & $\begin{array}{l}\text { est for } \\
\text { ariance }\end{array}$ & & & & & \\
\hline & $f$ & Sig. & $t$ & $\mathrm{df}$ & $\begin{array}{c}\text { Sig } \\
\text { (2-tailed) }\end{array}$ & $\begin{array}{c}\text { Mean } \\
\text { Difference }\end{array}$ & $\begin{array}{l}\text { Std. Error } \\
\text { Difference }\end{array}$ \\
\hline $\begin{array}{c}\text { Equal Variances } \\
\text { Assumed }\end{array}$ & 0.519 & 0.474 & 2.041 & 58 & 0.046 & 3.367 & 1.649 \\
\hline $\begin{array}{c}\text { Equal Variances } \\
\text { not Assumed }\end{array}$ & & & 2.041 & 57.834 & 0.046 & 3.367 & 1.649 \\
\hline
\end{tabular}

As Table 3 indicates, the results of the Levene's test $(f=.519, p=.474>.05)$ showed that the variances between the two groups were not significantly different and thus, homogeneity of variances was assumed. Therefore, the results of the $t$-test with equal variances assumed are reported here. The results $(t=2.041, \mathrm{df}=58, p=.046<.05)$ show that there was a significant difference between the mean scores of the two experimental groups at the post-test.

The differences observed between the sample means on the post-test (24.17 and 20.80 for non-task preparation activities and providing a model groups, respectively) were large enough to be attributed to the differences between the population means and therefore not due to sampling errors. It means that there was a significant difference between the effect of the non-task preparation activities technique and providing a model technique on EFL learners' vocabulary retention.

Moreover, the effect size was computed by Cohen's $\mathrm{d}$ and $\mathrm{r}$ using the $t$-value and df. Cohen's $\mathrm{d}$ came out to be .536 which according to Cohen's standard shows a medium effect. Cohen's d of .536 corresponds with r value of .26 yielding eta square of .067 which indicates that non-task preparation activities accounted for $6.7 \%$ of the 


\section{파망 \\ International Journal of Applied Linguistics \& English Literature \\ ISSN 2200-3592 (Print), ISSN 2200-3452 (Online)}

Vol. 1 No. 1; May 2012

variability in the vocabulary retention scores of the group. Therefore, the findings of the study could be considered moderate for the purpose of generalization.

\section{Discussion}

As a result of the data analysis, the null hypothesis of the research was rejected and the data moderately suggested that out of the two treatments given to the two experimental groups, use of non-task preparation pre-task activities had a significantly more effective impact on the vocabulary retention of the intermediate students.

Note has to be taken that in this study both groups received the same warm up and the same while-task activities and both practiced the vocabularies again during the identical post-task activities. Therefore, the justification for the higher impact of the non-task preparation activities may reside in the difference the two pre-task activities may possibly have in the mental processes they involve and the type of load each reduce for the learners. As discussed in the introduction, provide a model activity is argued to reduce the cognitive load by activating learners' content schemata (Ellis, 2006; Willis, 1996), while non-task preparation is said to minimize both the cognitive and linguistic demands of the task (Ellis, 2003) along with developing learners' schemata (Ellis, 2003). Therefore, it seems that in the case of provide a model, while the cognitive load is reduced, the learners still need to struggle with the linguistic features of the task with vocabulary being one of the fundamental ones. However, by means of the non-task preparation activities, both the cognitive and linguistic loads are minimized, leaving the participants with an advantage especially when the focus of the task, like this study, is learning and retention of vocabulary.

Another possible justification, which of course requires further research, might be the activation of different types of schemata by the two pre-task activities. As mentioned in the previous paragraph, provide a model seems to activate the content schemata and thus, the advantage of non-task preparation activities might lie in its probable influence on activating both formal and content schemata, a conjecture which definitely requires evidence obtained through research.

Yet, it might have also been the case that the non-task preparation activities resulted in a more student-centered practice in which the participants not only were more cognitively involved but also felt more responsible in finding the meaning of the vocabularies, and thus, became more autonomous. According to Weimer (2002), in a learner-centered context, the learners are more motivated, more involved or engaged, more creative, and more responsible for their learning, and as a result more learning takes place. Moreover, Rivers (2008) states that the focus of TBLT is on learner-centered educational philosophies. Therefore, an additional conclusion might be that non-task preparation activities better serve such a philosophy.

On the contrary, in the providing a model group the participants had to imitate the teacher rather than exploring the ways and means of doing the task themselves and as a result might have been more dependent upon the teacher and also less cognitively involved. Therefore, although Ellis (2006) asserts that teachers can scaffold learners' performance through the pre-task activities knowing that such other-regulation will in future result in self-regulation; it might have been the case that providing a model pre-task activity, kept the participants more dependent on the teacher. This interpretation entails taking the limited time span of this research into account. The conclusion might be that provide a model activity may result in a more gradual autonomy of the students if practiced for a period of time longer than the current study.

Finally, the results of this research, though limited in scope, suggest that using non-task preparation activities instruction in learning vocabularies and recalling them is useful for pre-intermediate learners. Consequently, attempts should be made to teach learners to be independent of using dictionaries or the teacher to present the meaning of the unknown vocabularies.

\section{Conclusion}

With the highly significant role that vocabulary plays in communication and thus in teaching and learning a foreign language along with the centrality TBLT has gained in foreign language teaching, the important issue is how and when to incorporate vocabulary into a TBLT syllabus to involve learners as much as possible and aid them in processing the vocabulary at a deeper level in order to have a higher degree of retention. The results of this study suggested that incorporating vocabulary in pre-task phase through non-task preparation activities brings about a significantly better retention in comparison to providing a model activity.

Therefore, it can be concluded that findings of this study may have implications for foreign language teachers in raising their awareness regarding the importance of the pre-task phase and the effectiveness of non-task preparation activities when the focus is vocabulary retention. Moreover, syllabus designers and materials developers are encouraged through the findings of this study to design more innovative non-task preparation activities and incorporate them into the text books.

Page $\mid 120$ 
International Journal of Applied Linguistics \& English Literature

ISSN 2200-3592 (Print), ISSN 2200-3452 (Online)

Vol. 1 No. 1; May 2012

This study does not put an end to the research on the effectiveness of using non-task preparation activities. Further study is needed to compare the effect of these two pre-task activities at different levels of language proficiency and on different language components or skills. Furthermore, in another research, other pre-task alternatives, strategic planning and performing a similar task, and any combination of them can be compared. Ultimately, according to Cui and Wang, Li, and Nurweni (all cited in Zheng, 2011) who believe that there is a direct relation between vocabulary depth (being processed deeply) and vocabulary breadth (vocabulary size), further studies can compare the impact of different pre-task activities on such a relationship.

\section{References}

Beglar, D., \& Hunt, A. (2002). Implementing task-based language teaching. In J. C. Richards \& W. A. Renandya (Eds.), Methodology in language teaching: An anthology of current practice (pp. 96-106). Cambridge: Cambridge University Press.

Boston, J. S. (2008). Learner mining of pre-task and task input. English Language Teaching, 62(1), 62-66.

Brown, H. D. (2001). Teaching by principles: An interactive approach to language pedagogy (2nd ed.). Longman: Pearson Education Company.

Bygate, M. (1999). Quality of language and purpose of task: Patterns of learners' language on two oral communication tasks. Language Teaching Research, 3(3), 185-214.

Chen, I. J. \& Chen, Ch. W. (2008). Cross-border telecommunication: A task-based collaboration at college level. The Journal of Asia TEFL, 5(4), 163-189.

Craik, F. I. M. \& Lockhart, R. S. (1972). Levels of processing: A framework for memory research. Journal of Verbal Learning and Verbal Behavior, 11, 671-684.

Craik, F. I. M. \& Tulving, E. (1975). Depth of processing and the retention of words in episodic memory. Journal of Experimental Psychology, 104(3), 268-294.

Crooks, G., \& Chaudron, C. (1991). Guidelines for language classroom instruction. In M. In M. Celce - Murcia (Ed.), Teaching English as a second or foreign language (3rd ed., pp. 29-42). Boston: Heinle \& Heinle.

Dörnyei, Z. (2001). Motivational strategies in the classroom. Cambridge: Cambridge University Press.

Ellis, R. (2003). Task-based language learning and teaching. Oxford: Oxford University Press.

Ellis, R. (2006). The methodology of task-based teaching. Asian EFL Journal, 8(3), 1-17.

Hulstjin, H. J. Laufer, B. (2001). Some empirical evidence for the involvement load hypothesis in vocabulary acquisition. Language Learning, 51(3), 539-558.

Lee, J. (2000). Tasks and communicating in language classrooms. Boston: McGraw-Hill.

Lee, L., \& Gunderson, E. (2001). Select reading. Oxford: Oxford University Press.

Liu, J. (2011). The effects of glossing on incidental vocabulary learning through reading-based oral tasks. The Journal of Asia TEFL, 8(3), 221-241.

Lockhart, R. S. \& Craik, F. I. M. (1990). Levels of processing: A retrospective commentary on a framework for memory research. Canadian Journal of Psychology, 44(1), 87-112.

Miller, G. A. (1956). The magical number seven, plus or minus two: Some limits on our capacity for processing information. Psychological Review, 63, 81-97.

Nemati, A. (2010). Enhancing long-term retention by memory vocabulary learning strategies. The Journal of Asia TEFL, 7(1), 171-195.

Nunan, D. (2001). Second language teaching and learning. Boston: Heinle \& Heinle.

Nunan, D. (2004). Task-based language teaching. Cambridge: Cambridge University Press.

Prabhu, N. S. (1987). Second language pedagogy. Oxford: Oxford University Press.

Richards, J. C. (1999). Addressing the grammar gap in task work. In J. C. Richards \& W. A. Renandya (Eds.), Methodology in language teaching: An anthology of current practice (pp. 153-166). Cambridge: Cambridge University Press.

Richards, J. C., \& Rodgers, T. S. (2001). Approaches and methods in language teaching (2nd ed.). Cambridge: Cambridge University Press.

Rivers, D. J. (2008). Task design to task enactment: How teacher interpretations of a given task manipulate its evolution as a pedagogical construct. The Journal of Asia TEFL, 5(3), 31-54.

Schmitt, N. \& Schmitt, D. (1995). Vocabulary notebooks: Theoretical underpinnings and practical suggestions. English Language Teaching, 49(2), 133-143.

Schmitt, N. (2000). Vocabulary in language teaching. Cambridge: Cambridge University Press.

Skehan, P. (1996). A framework for the implementation of task-based instruction. Applied Linguistics, 17(1), 38-62.

Page $\mid 121$ 


\section{International Journal of Applied Linguistics \& English Literature}

ISSN 2200-3592 (Print), ISSN 2200-3452 (Online)

\section{Vol. 1 No. 1; May 2012}

Skehan, P. (2003). Task-based instruction. Langauge Teaching, 36, 1-14.

Tajeddin, Z. \& Chiniforoushan, N. (2011). Visual intelligence and lexical enhancement tasks: Their impacts of EFL learners' receptive and productive vocabulary. The Journal of Asia TEFL, 8(3), 109-134.

Vasiljevic, Z. (2009). Incorporating rich vocabulary instruction into a language classroom. The Journal of Asia TEFL, 6(1), 189-214.

Verhelst, M. (2002). A box full of feelings: Promoting infants' second language acquisition all day long. In K. Van den Branden (Ed.), Task-based language education: From theory to practice (pp. 197-216). Cambridge: Cambridge University Press.

Wang, L. (2009). An empirical study of differences in the use of English vocabulary learning strategies. The Journal of Asia TEFL, 6(4), 151-192.

Willis, D. (1990). The lexical syllabus. Birmingham: Colins Coubuild English Language Teaching. Willis, J. (1996). A framework for task-based learning. Oxford: Longman. Willis, D., \& Willis, J. (2007). Doing task-based teaching. Oxford: Oxford University Press.

Weimer, M. (2002). Learner-centered teaching. San Francisco: Jossey-Bass.

Zheng, Y. (2009). Exploring Chinese EFL learners' receptive and productive vocabulary knowledge: Implications for EFL vocabulary teaching. The Journal of Asia TEFL, 6(1), 163-188.

Zheng, Y. (2011). Exploring Chinese EFL learners' vocabulary depth knowledge: The role of L1 influence. The Journal of Asia TEFL, 8(3), 191-219.

Zimmerman, C. B. (1997). Historical trends in second language vocabulary instruction. In J. Coady \& T. Huckin (Eds.), Second language vocabulary acquisition: A rationale for pedagogy (pp. 5-15). Cambridge: Cambridge University Press. 